This is the peer reviewed version of the following article:

Pousa, C. and Mathieu, A. (2014), The Influence of Coaching on Employee Performance: Results From Two

International Quantitative Studies. Performance Improvement Quarterly, 27(3), 75-92. doi:10.1002/piq.21175

which has been published in final form at doi:10.1002/piq.21175. This article may be used for non-commercial

purposes in accordance with Wiley Terms and Conditions for Self-Archiving.

\title{
The influence of coaching on employee performance: Results from two international quantitative studies
}

\author{
Claudio Pousa, DBA. Faculty of Business, Lakehead University, Canada \\ Ane Mathieu, Ph.D. Faculté d'Administration, Université de Sherbrooke, Canada
}

\begin{abstract}
Coaching has been identified as a key managerial behavior that organizations must promote to develop employees and achieve higher levels of performance. Despite this agreement and an increasing interest in coaching, there is still a paucity of studies exploring the impact of coaching on individual performance. This paper presents an empirical investigation from two international field studies, one using B-to-B salespersons working in Latin America and the other one using B-to-C frontline employees from a service organization in Canada. Building on Leader-Member Exchange Theory we propose that coaching increases individual performance beyond the potential impact of sales experience and tenure. We find that coaching can explain between $2.9 \%$ and $6.2 \%$ of the variance in performance when controlling for tenure and experience. The paper makes several scientific and managerial contributions, and also opens new avenues for research.
\end{abstract}

Keywords: employee coaching, performance, business-to-business, business-to-consumer

\section{Quotes}

"Leaders usually initiate the exchange by providing more information, support and assistance. They give subordinates higher levels of latitude to perform their jobs, thus contributing to subordinates' job enrichment".

"Coaching could explain $6.2 \%$ of the variance in performance when controlling for experience and tenure" 


\section{The influence of coaching on employee performance: Results from two international quantitative studies}

\section{Introduction}

\subsection{Research Problem}

The last few decades have shown an increasing pace of change in the business environment, with new competitors entering in and struggling for stagnant markets. This increasing competition has forced organizations to make additional efforts to develop and keep competitive advantages and to proactively respond to a more complex business environment (Hagen, 2012). In this context, research and transference of managerial tools aimed at increasing employee performance has become critical (Pousa, 2012; Pousa and Mathieru, 2010). One particular managerial tool, the coaching of the sales force, has been specially praised by practitioners and scholars as key to develop subordinates and help them achieve higher levels of performance (Corcoran et al., 1995; Deeter-Schmelz et al., 2002, 2008; Ellinger and Bostrom, 1999; Pousa, 2012; Richardson, 2009).

The use of coaching in organizations started to appear in peer-reviewed journals in the late 1930s (Grant, 2011) and continued at a steady pace since then. However, since the 2000s the number of publications addressing different types of coaching in organizations increased dramatically (Grant, 2011; Hagen, 2012; Pousa, 2012).

Despite the seeming abundance of research in coaching in organizational settings, several authors identified two important gaps. The first one, is the paucity of research on the impact of coaching on employee and organizational performance (Grant and Cavanaugh, 2004; Hamlin et al., 2006; McLean et al., 2005; Hagen, 2012). This gap led to recent calls to explore the effectiveness of coaching in improving performance (Cassidy and Medsker, 2009). A second gap is that the expected relationship between coaching and performance has not been adequately explained, in the sense that there are very few studies that identified mediating variables between coaching and performance (Pousa, 2012; Pousa and Mathieu, 2014).

We decided to address the first gap in the literature, and explore whether coaching by the manager affects employee performance or not (research question). Accordingly, we conducted two field studies with the purpose of testing the relationship between the managerial coaching and employee performance.

\subsection{Purpose of the paper}

The goal of this paper is to contribute to the literature investigating the impact of coaching on performance, by reporting the results from two international quantitative studies. One of the studies used a sample of business-to-business employees working in one of the central countries in Latin-America for an American industrial manufacturer. The other sample consisted of frontline employees, holding sales responsibilities at one of the biggest regional banks in Central Canada.

\subsection{Paper structure}

The paper starts presenting a focused literature review on coaching in organizations. Next, the theoretical framework and the hypothesis are presented, following by the methodology and analysis. Finally, the discussion section presents the key scientific and managerial implications of the research as well as the avenues of future research.

\section{Literature review}

\subsection{Definition and characteristics of coaching}

Coaching has been defined as a process for improving work performance (Fournies, 1978); as a one-to-one process of helping others to improve, to grow and to get to a higher level of performance, by providing focused feedback, encouragement and raising awareness (Corcoran et al., 1995; Hargrove, 1995; Heslin et al., 2006; Orth et al.,1987; Richardson, 2009; Whitmore, 1985); and as a developmental process that enables and empowers people (Evered and Selman, 1989) and opens new opportunities for learning through which improved performance is attained (Ellinger and Bostrom, 1999; Ellinger et al., 2003).

Several studies differentiated coaching from other helping behaviors, like mentoring or counselling (D'Abate et al, 
2003; Ellinger, 2003; Hagen, 2012). These studies consider mentoring as a guiding relationship led by a senior executive who provides advice, information and emotional support to a younger employee on a voluntary basis, while counselling is more concerned with the employee's emotional state as it affects performance (D'Abate et al, 2003; Ellinger, 2003; Hagen, 2012).

In business settings, two main streams of research emerged. One of these streams concerns research on executive coaching. In executive coaching, a top-level executive (usually the CEO, but it could also be one of his/her direct reports) is being coached by an external consultant with the purpose of helping this individual achieve mutually identified goals, improve his/her professional performance and personal satisfaction, and consequently improve the effectiveness of the organization (Joo, 2005; Kilburg, 1996).

The other stream of research concerns managerial coaching, also identified as the manager-as-coach model, employee coaching or simply coaching as it is used in this article. In this case, any manager in the company can use coaching as a managerial tool to help his/her subordinates achieve a series of externally-set organizational goals and increase their job-related performance. Although coaching and executive coaching share some aspects in common and they both arise from similar roots (Hagen, 2012) research has seen them as two different constructs (D'Abate et al., 2003; Hagen, 2012; Pousa, 2012), and also different from other directive managerial behaviors like supervising, managing or providing feedback (Ellinger and Bostrom, 1999; Good, 1993; Ingram et al., 2005; McLean et al., 2005; Pousa, 2012; Rich, 1998; Richardson, 2009).

This paper is focused on the use of coaching by managers in order to help their subordinates achieve higher performance through facilitation and discovery. Building on Ives (2008), we define coaching as a non-directive, goal-focused and performance-driven intervention led by the manager.

\subsection{Antecedents and consequences of coaching}

Concerning the antecedents of coaching, scholars identified a number of skills that managers must have in order to conduct it (Gilley et al., 2010; Graham et al., 1993, 1994; Orth et al., 1987), the proper organizational climate for coaching (Ellinger et al., 2005; Everett and Selman, 1989), the organizational focus on long- or short-term results (Pousa and Mathieu, 2010) and the situations that trigger a coaching intervention (Ellinger, 2003).

Concerning the consequences of coaching, both practitioners and scholars have praised the positive consequences of coaching on job satisfaction, performance, commitment, and employee development. The rationale for this statement is that in a coaching context, people will feel more valued and respected by their employers, thus they will tend to be more loyal and work harder. Furthermore, more developed people will have higher job-related competencies, perform better and obtain higher customer satisfaction (Ellinger et al., 2005). Two recent qualitative studies provide initial support to these statements; both salespeople and sales managers agreed that coaching skills impact salesperson's development, which ultimately increases salesperson's job performance and customer relationships development (Deeter-Schmelz et al., 2002, 2008).

Recently, scientific interest in coaching increased. Some studies found that coaching might reduce salesperson manipulative and deviant behaviors like lying (Mathieu and Pousa, 2011) or sales-orientation (Pousa and Mathieu, 2014). Also, that coaching can increase salesperson relational behaviors, like customer-orientation (Pousa and Mathieu, 2014), commitment and motivation (Onyemah, 2009), job satisfaction (Agarwal et al., 2009; Ellinger et al., 2005; Onyemah, 2009) and performance (Agarwal et al., 2009; Pousa, 2012; Trépanier, 2010).

\section{Theoretical framework}

\subsection{Hypothesis}

Three key components of the coaching construct are supervisory feedback, role modeling and trust between the coach and the subordinate (Rich, 1998). Through the coaching intervention, the manager-as-coach "encourages and motivates employees to learn, and helps to surface and test assumptions ... is highly learner-centered and focuses on collaboration and discovery" (Ellinger and Bostrom, 1999). The coach is a resource who uses his knowledge and skills to help subordinates became aware of their flaws and responsibilities, propose changes and solutions, and commit themselves with their implementation (Richardson, 2009; Whitmore, 1985) by means of a facilitative process of discovery and awareness.

One of the most important tools used in this kind of coaching processes is questioning; through the use of precise questions, the coach guides the salesperson's reflection, helping him to diagnose the problem and to propose a 
solution (Whitmore, 1985). Accordingly, the locus of knowledge is located within the employee, and the coach becomes a facilitator of employee discovery, learning and development (Agarwal et al., 2009; Ellinger and Bostrom, 1999; Ellinger et al., 2003; Evered and Selman, 1989; McLean et al., 2005). Through this process the manager and the subordinate develop a high-quality relationship that allows them to work in an open and collaborative way, characterized by exchange in the form of greater empowerment, commitment, harder work and increased tolerance for errors.

These variables also describe what happens in high-quality exchanges as depicted in the Leader-Member Exchange (LMX) Theory (Dansereau et al., 1975; Gerstner and Day, 1997; Graen and Uhl-Bien, 1995; House and Aditya, 1997). Building on the Social Exchange framework and Role Theory, LMX establishes that a leader can develop high-quality relationships with his subordinates; these relationships are characterized by high degrees of mutual trust, respect and obligation between both parties (Dansereau et al., 1975; Graen and Uhl-Bien, 1995; Liden and Maslyn, 1998; Sparrowe and Liden, 1997).

In LMX relationships, leaders usually initiate the exchange by providing more information, support and assistance. They give subordinates higher levels of latitude to perform their jobs, thus contributing to subordinates' job enrichment. Subordinates reciprocate by taking additional responsibilities, developing ownership feelings toward the unit and its goals, and providing more effort and commitment in the pursuit of mutual interests (Dansereau et al., 1975; Graen and Uhl-Bien, 1995; Gerstner and Day, 1997; House and Aditya, 1997; Ilies et al., 2007; Lee, 2005; Liden and Maslyn, 1998; Sparrowe and Liden, 1997).

Scholarly research in coaching used the Social Exchange framework (Mathieu and Pousa, 2011) and LMX as key theoretical frameworks to study coaching relationships and consequences (Agarwal et al., 2009; Onyemah, 2009; Pousa, 2012; Pousa and Mathieu, 2014; Trépanier, 2010). A key consequence of high-quality LMX relationships is their positive impact on subordinate performance. A recent meta-analysis on the consequences of LMX on performance and other organizational constructs found a positive correlation between LMX and performance (Gerstner and Day, 1997) and other scholars also found a positive correlation between coaching and performance (Agarwal et al., 2009; Ellinger et al., 2005; Trépanier, 2010). Accordingly, we propose that:

H1: It is hypothesized that, when controlling for selling experience and tenure, a positive relationship exists between coaching and subordinate performance

\subsection{Control variables}

It was proposed in the literature that some demographic variables, like selling experience or tenure in a given position can affect the individual motivation to perform through their effect on expectancy and valences and thus, affect performance (Cron et al., 1988). Similar concerns were expressed in a coaching context in the sense that age or organizational tenure might moderate the effect of coaching on behavioral variables (Onyemah, 2009; Trépanier, 2010).

In order to rule out the possibility that selling experience, tenure in the position or tenure with the company might inflate or deflate the results of our study, we decided to incorporate these variables as control variables in our model.

\section{Method}

\subsection{Research design and data collection procedure}

The hypothesis was tested using a non-experimental design. Two purposive samples consisting of salespeople from two different companies were invited to participate in the study. Sample 1 consisted of business-to-business salespersons from a variety of industries (Oil \& Gas, Telecommunications, Abrasives, etc.) working at a Latin American branch of a large American industrial manufacturer. Sample 2 consisted of frontline employees (Financial Advisors and Financial Planners) from a large business-to-consumer, financial services organization in Canada.

Previous research on coaching also used non-experimental designs and purposive samples (Agarwal et al., 2009; Ellinger et al., 2003, 2005; Onyemah, 2009; Trépanier, 2010; Pousa, 2012; Pousa and Mathieu, 2014). This is an undisputable choice, considering that coaching is a managerial behavior that takes years to be learned and developed, and it cannot be easily replicated in laboratory settings. For this study, the companies were selected because both 
had implemented coaching programs several years ago, and managers had been coaching their subordinates for many years on a regular basis. At the time of the study, no other factors that could affect performance (e.g.: additional training, sales promotions, changes in the remuneration structures) were under consideration or implementation by any of the companies.

The two companies were initially contacted by the researchers, and they agreed to participate by allowing their salespersons to voluntarily complete the questionnaire in office time and by providing the working e-mails of these individuals. A contact person was also appointed in each of the companies to make the proper introductions.

Potential respondents from the two participating companies received an introductory e-mail from the corresponding contact person. Following this initial contact, they received a mail from one of the researchers inviting them to complete a web-based survey hosted in a secured site. In this mail, the academic aspects of the research were emphasized, as well as the confidentiality of all the information provided by the participants. A second follow-up mail was sent two weeks later to remind them to complete the survey.

\subsection{Measures}

Measuring scales were adapted from the literature in coaching and sales management. Employee coaching was measured using 8 items from Ellinger et al. (2003) and performance was measured using 7 items from Fang et al. (2004) scale. Scales were anchored at $1=$ strongly disagree and $7=$ strongly agree.

\subsection{Scale translation}

The items were originally developed in English but for the purposes of this research they demanded some additional adaptations. In the case of the Canadian bank, the sample consisted of English and French speaking respondents; in the case of the American manufacturer, there were Spanish speaking respondents.

English scales were translated into French and into Spanish using the parallel-blind technique (Guthery and Lowe, 1992; Mathieu et al., 2000). Two sets of translators were used: one for the English to French version, and the other one for the English to Spanish version. In the parallel-blind technique, two translators independently translated the scale from the source into the target language; after that, the translators compare their versions and work out their differences into a final version; the quality of the final result is high because it combines the advantages of individual results with a collaborative effort.

\section{Analysis}

\subsection{Samples}

Invitations were sent to 460 individuals and 176 complete questionnaires were received for a response rate of $38 \%$. Demographic characteristics of the individual samples are shown in Table 1.

Table 1. Sample characteristics

\begin{tabular}{|l|c|c|}
\hline & Sample 1 & Sample2 \\
\hline Invitations sent & $\begin{array}{c}\text { B-to-B salespersons } \\
\text { (Latin America) }\end{array}$ & $\begin{array}{c}\text { B-to-C frontline employees } \\
\text { (Canada) }\end{array}$ \\
Responses received & 87 & 373 \\
Response rate & 62 & 114 \\
\hline Female & $71.3 \%$ & $30.6 \%$ \\
Male & $24.2 \%$ & $69.9 \%$ \\
Tenure with the company (years) & $75.8 \%$ & $30.1 \%$ \\
Tenure in the position (years) & $5.68(5.52)^{*}$ & $13.14(13.08)^{*}$ \\
Years of selling experience & $5.10(5.10)$ & $8.98(8.62)$ \\
* Mean (std.dev.) & $11.69(7.16)$ & $15.03(9.91)$ \\
\hline
\end{tabular}


As can be seen from Table 1, the industrial sample (Sample 1) was mainly composed of males $(75.8 \%)$ while the service sample (Sample 2) was mainly composed by females $(69.9 \%)$. Concerning tenure with the company and in the position, both samples were highly heterogeneous with standard deviations almost as high as the mean values, suggesting an even distribution of new and old employees.

Concerning sales experience, both samples also showed high mean values (11.69 and 15.03 years) suggesting a group of experienced employees. However, high standard deviation values also suggest a very heterogeneous sample, covering a broad range of experienced and inexperienced individuals.

\subsection{Reliability and validity of measuring scales}

Confirmatory factor analysis was used to estimate the properties of the measurement model, which was estimated by restricting each scale's item loading on its a priori specified factor, and allowing free correlation among factors (Gerbing and Anderson, 1988). All standard regression weights were higher than .60 so all items from the original scales were retained. Final factor loadings and reliabilities are showed in Table 2.

Table 2. Construct items and factor loadings

\begin{tabular}{|l|c|c|}
\hline Coaching & $\begin{array}{c}\text { Item-total } \\
\text { correlations }\end{array}$ & $\begin{array}{c}\text { Factor } \\
\text { loadings }\end{array}$ \\
My coach ... & .794 & .799 \\
$\ldots$ uses analogies, scenarios and examples to help me learn. & .741 & .756 \\
$\ldots$ encourages me to broaden my perspectives by helping me to see the big picture. & .814 & .860 \\
$\ldots$ provides me with constructive feedback. & .800 & .842 \\
$\ldots$ solicits feedback from me to ensure that his/her interactions are helpful to me. & .826 & .867 \\
$\ldots$ provides me with resources so I can perform my job more effectively. & .765 & .796 \\
$\ldots$ asks questions rather than provide solutions, to help me think through issues. & .695 & .731 \\
$\ldots$ sets expectations with me and communicates the importance of those & & \\
expectations to the broader goals of the organization & .635 & .653 \\
$\ldots$ role-plays with me to help me see different perspectives. & & \\
Performance & & \\
I am very effective in ... & .568 & \\
$\ldots$ in contributing to my firm's market share. & .556 & .603 \\
$\ldots$ in selling products with the highest profit margins. & .793 & .640 \\
$\ldots$ generating a high level of dollar sales. & .663 & .877 \\
$\ldots$ quickly generating sales of newly introduced products. & .721 & .721 \\
$\ldots$ identifying major accounts in my territory. & .743 & .688 \\
$\ldots$ selling to major accounts. & .701 & .707 \\
$\ldots$ exceeding annual sales targets and objectives. & .756 \\
\hline
\end{tabular}

We assessed scales' reliability using three different indicators: Cronbach's alpha, corrected item-total correlations and composite reliability. Cronbach's alpha for coaching was .929 and for performance .884 (Table 3), well above the accepted threshold of 0.7 that suggests acceptable reliability (Nunnally, 1978). Concerning corrected item-total correlation, scales presented values ranging from .556 to .826 (Table 2), all of them also above the accepted threshold that suggests acceptable reliability. Finally, composite reliability indexes ranged from .880 for performance to .930 for coaching (Table 3), also exceeding the threshold of 0.6 , necessary for measurement reliability (Bagozzi and Yi, 1988; Fornell and Larcker, 1981). Globally, these results suggest that the scales present good reliability.

The average variance extracted (AVE) rendered values of .626 for coaching and .515 for performance (Table 3), also suggesting adequate convergent validity (Fornell and Larcker, 1981).

Discriminant validity of the measures was assessed by comparing the square root of the AVE values to the factor correlations; the results indicate that the square root of AVE for each factor is bigger than its correlations (Table 3), suggesting adequate discriminant validity (Fornell and Larcker, 1981). 
Table 3. Factor correlations

\begin{tabular}{|l|ccccc|cc|}
\hline & Mean & SD & $\alpha$ & CR & AVE & Coaching & Performance \\
\hline Coaching & 5.131 & 1.108 & .929 & .930 & .626 &. $\mathbf{7 9 1}$ & $.279^{*}$ \\
Performance & & & & & & & $.212^{*}$ \\
\hline
\end{tabular}

AVE is the Average Variance Extracted. For each factor the square root of AVE is presented in the main diagonal

Correlations above the main diagonal correspond to sample 1. Below the main diagonal correspond to sample2

* correlations are significant at 0.05 level (2-tailed)

The fit indexes for the measuring model indicated a very good fit between the model and the data (Byrne, 2010; Kline, 2011) with $\chi^{2}=119.44, \mathrm{p}<.01 ; \chi^{2} / \mathrm{df}=1.39$; Comparative Fit Index $(\mathrm{CFI})=.98$; root mean square error of approximation $($ RMSEA $)=.05$, Hi 90 RMSEA $=.07$; Incremental Fit Index $($ IFI $)=.98$; and Tucker Lewis Index $(\mathrm{TLI})=.97$.

\subsection{Results}

After the measuring model was deemed to be acceptable, we tested the main hypothesis using stepwise linear regression. First, we introduced control variables to the regression (tenure with the company, tenure in the position, and years of sales experience). In the following step we introduced the main effect (coaching) and assessed its effect on the dependent variable (performance) by analyzing whether the additional explained variance in the dependent variable was significant or not.

As hypothesized, coaching positively affects performance $(\beta=.280, p<.05$ for sample 1 , and $\beta=.200, p<.05$ for sample 2) in support of our main hypothesis. The percentage of variance explained of the dependent variable once the effect of the control variables was eliminated was small but significant for both samples $\left(\Delta \mathrm{r}_{\mathrm{adj}}{ }^{2}=.062\right.$ for sample 1 and $\Delta \mathrm{r}_{\text {adj }}{ }^{2}=.029$ for sample 2) thus, suggesting that the use of coaching by the manager can have a significant positive effect on salesperson performance (Table 4).

Table 4. Standardized regression weights and explained variance for the stepwise linear correlation

\begin{tabular}{|l|c|c|c|c|}
\hline & \multicolumn{2}{|c|}{$\begin{array}{c}\text { Industrial sample } \\
\text { (Business-to-business) }\end{array}$} & \multicolumn{2}{c|}{$\begin{array}{c}\text { Service sample } \\
\text { (Business-to-consumer) }\end{array}$} \\
\hline Control variables & n.s. & n.s. & n.s. & n.s. \\
Years at the company & n.s. & n.s. & n.s. \\
Years at the position & n.s. & n.s. & n.s. \\
Selling experience & -.026 & & -.005 & \\
$\mathrm{r}_{\text {adj }}^{2}$ & n.s. & & n.s. & \\
$\Delta \mathrm{r}_{\text {adj }}^{2}$ & & & & $.200^{*}$ \\
\hline$\underline{I n d e p e n d e n t ~ v a r i a b l e ~}_{\text {Coaching }}$ & & $.280^{*}$ & & .024 \\
$\mathrm{r}_{\mathrm{adj}}^{2} \mathrm{r}_{\mathrm{adj}}^{2}$ & & .036 & & $.029^{*}$ \\
\hline$* \mathrm{p}<.05$ & & $.062 *$ & & \\
\hline
\end{tabular}

\subsection{Assessment of the Effects of Same-Source Bias}

Our data relied on information provided by one type of respondent for both predictor and criterion variables. In this situation, a self-report bias might result from any artifactual covariance between these variables due to the fact that the person providing both answers is the same (Podsakoff et al., 2003). Research has typically accepted that 
common method variance (CMV) might inflate or deflate correlations between constructs (Cote and Buckley, 1987; Podsakoff et al., 2003), although some scholars have proposed that CMV does not automatically affect or distort these correlations (Schmidtt, 1994; Spector, 1987, 1994, 2006).

One of the most widely used techniques for diagnosing the likeliness of CMV is the Harman's single factor test (Podsakoff et al., 2003). Following this technique, we loaded all the variables in the study into an exploratory factor analysis and we examined the unrotated factor solution. Data suggested the need of three factors to account for a significant percentage of variance (64.6\%). In this solution, the first factor accounted for only $38.7 \%$ of the extracted variance, thus suggesting that there is not a substantial amount of common method variance present in the measures (Podsakoff et al., 2003).

\section{Discussion}

Coaching is a key managerial behavior that can be used in organizational settings to develop subordinates and help them achieve increasing levels of performance. Despite its importance, the number of studies exploring the relationship between coaching and performance is limited. In order to contribute to this stream of research we present an initial empirical investigation from two different field studies. In the first one, respondents were business-to-business salespersons working in Latin America. In the second one, we used a sample of frontline employees from a service business-to-consumer organization in Canada.

Building on LMX theory, we proposed that the coaching provided by the manager would help subordinates increase their job performance. We tested this relationship using scales found in the literature and controlling for years of selling experience, tenure with the company and tenure in the positions. Both studies supported the hypothesis that coaching increases employee performance beyond the effect that can be attributable to the control variables.

Results from the first sample (Latin-American business-to-business salespeople) suggested that coaching could explain $6.2 \%$ of the variance in performance when controlling for experience and tenure $\left(\Delta \mathrm{r}_{\mathrm{adj}}{ }^{2}=.062, \mathrm{p}<.05\right)$. Results from the second sample (Canadian business-to-consumer front-line employees with sales responsibilities) suggested that coaching could explain $2.9 \%$ of the variance in performance when controlling for experience and tenure $\left(\Delta \mathrm{r}_{\text {adj }}^{2}=.029, \mathrm{p}<.05\right)$.

\subsection{Scientific contributions}

Results not only support our hypothesis, but also go in a similar direction than other studies recently published in the scientific literature. Trépanier (2010) also found a positive effect of coaching on salesperson performance $\left(\Delta \mathrm{r}_{\mathrm{adj}}{ }^{2}=.11\right.$, $\mathrm{p}<.01)$, as well as Agarwal et al. (2009) $\left(\Delta \mathrm{r}^{2}=.13, \mathrm{p}<.01\right)$ and Pousa and Mathieu (2014) $\left(\mathrm{r}^{2}=.10, \mathrm{p}<.01\right)$. In logistics environments, Ellinger et al. (2005) also found that coaching can explain an increase in warehouse worker job-related performance $\left(\mathrm{r}^{2}=.18\right.$, although this value includes the additional effect of experience, wages and training). Given the paucity of empirical studies exploring the effectiveness of coaching as a strategy for improving performance (Grant and Cavanaugh, 2004; Hagen, 2012) and the call for more research in this area, we consider this one the main scientific contribution of our study.

A second contribution concerns the choice of a theoretically based approach to address the research problem. One of the strong critics to research in coaching is that it has been predominantly practice-driven and guru-led, lacking solid theoretical basis, as well as being mostly based on single-case studies (Ellinger et al., 2008; Grant and Cavanagh, 2004; Hamlin et al., 2006). Several authors called for the development of more general, theoretically based research studies, which findings could be transferred to other domains and generalized to other populations.

In our case, the use of a non-probabilistic sample could raise questions regarding whether the conclusions of the study could be used in different settings. Although one of the necessary conditions to external generalizability is the use of probabilistic samples, this criterion has not been respected in most organizational research. Schwab (1985) recognizes this when he expresses that "almost all of the empirical studies published in our journals ... use convenience samples ... thus if one took generalization to a population using statistical inference seriously, one would recommend rejecting nearly all manuscripts submitted" (Schwab, 1985, p. 173, cited by Robson, 2002, p. 267). In qualitative research, where researchers strongly rely on non-probabilistic samples, scholars have proposed to talk of transferability rather than generalizability (Guba and Lincoln, 1989). Other scholars have stressed the importance of aspects like the presumed universality of the phenomenon studied as factors enabling the generalizability of results to other contexts when nonrandom samples are used (Maxwell, 1997). In the case of this 
study, there are no reasons to infer that the salespeople working for these companies are any different from other generic salespersons concerning the variables that could explain responses to coaching behaviors. Additionally, our hypothesis was theoretically derived from a widely accepted leadership theory, thus, the use of a convenience sample does not preclude the possibility of generalizing the expected results to a larger population of salespeople reporting to managers using non-directive, solution-focused, performance-driven coaching approaches.

The results of this study also provide additional support for the use of leader-member exchange as a valid theoretical framework to analyze coaching exchanges. We consider this as a third and final scientific contribution of our study. In the Theoretical Framework section we assumed that LMX was a significant theory to explain the high quality exchanges that take place in a coaching relationship and the positive consequences on salesperson behavior and performance. LMX theory establishes that a manager can develop high-quality relationships or exchanges with some of his subordinates, "characterized by high levels of trust, interaction, support and formal and informal rewards" (Ilies et al., 2007). The quality of this relationship affects important leader and member attitudes, behaviors and outputs (Gertsner and Day, 1997; House and Aditya, 1997; Ilies et al., 2007). LMX meta-analysis found that high quality relations between leaders and followers can explain between $9 \%$ and $30 \%$ of followers' performance ratings (Gerstner and Day, 1997). Our results suggest that coaching by the sales manager can explain a significant percentage of salesperson's performance. They go in the same direction than those found in LMX and coaching research and, thus, support our decision of using this theoretical approach.

\subsection{Managerial implications}

In today's business environment, the quest for efficiency and productivity has become of utmost importance. At all levels of the organizational hierarchy employees, middle-management and top-management are under an increased pressure to achieve higher performance in their respective roles. Our findings suggest that by using coaching managers can achieve higher role performance by helping their subordinates increase their own job performance.

Another implication for managers concerns the quantification of the impact of coaching on employee performance. Although this impact is not very strong, it is noticeable. Accordingly, managers performing coaching with their subordinates should see an increase in their performance after some interventions. This would help them evaluate also how effective they were in providing coaching. If no performance increment is seen, then the manager could question himself whether he is providing good coaching or any other factors could be hindering with subordinate performance. The analysis or the measuring items in Table 2 can guide the conscious manager who analyzes his coaching performance critically.

Following the same line of thought, items in Table 2 can help the manager in preparing the coaching intervention. It was proposed that some coaching interventions take place on-the-go, in a more informal way, while others are pre-programmed and are more formal in nature (Richardson, 2009). While getting ready for a pre-programmed, formal coaching intervention, the manager could go through the items in Table 2 to prepare a more effective coaching conversation.

Finally, our results contribute to the literature quantifying the effects of coaching on performance. In the case or organizations willing to implement or develop coaching programs, these results can help them estimate the potential impact on their performance and the return of their investments in the program. This is also a way of improving organizational decision-making.

\subsection{Limits of the study}

One of the limitations of our study is the use of purposive samples. The rationale for this rests in two facts. The first is that we needed respondents who were actually receiving coaching from their supervisors to evaluate its impact on performance. We couldn't guarantee that in a general population of salespeople most of them were receiving coaching, so in order to reach a useful sample to test our hypothesis we decided to use purposive samples. The second fact is that the concept of coaching is becoming very popular and people decide to use it to describe many interactions that could not be categorized as coaching. This was already stated elsewhere (Pousa, 2012) and the fact remains that within a random sample of salespeople many would call the intervention coaching when it is something different, thus introducing error in the measures and its correlations. We believe that the reasons for choosing a purposive sample are compelling, but nevertheless they remain a limit of this research.

Another limitation is that we used a single respondent to provide information about dependent and independent variables. This is an issue that drew the attention of scholars because using a single source of information might introduce a bias and inflate or deflate the results of a study (Cote and Buckley, 1987; Podsakoff et al., 2003; 
Schmidtt, 1994; Spector, 1987, 1994, 2006). Although the potential effects of common method bias have been analyzed by many scholars, there is no agreement that using a single respondent automatically introduces a bias (Schmidtt, 1994; Spector, 1987, 1994, 2006). In order to evaluate this possibility we assessed the potential effect of a common source bias using the Harman's single factor test as described in Podsakoff et al. (2003). Even our results suggest that there is not a substantial amount of common method variance present in the measures, the use of a single respondent to provide information about dependent and independent variables remains another limit of the study.

Finally, although we ruled out the potential effect of some variables like tenure and experience, others, like training or informal coaching received from peers, were not considered. This limit might be addressed in future studies.

\subsection{Avenues for further research}

Further to the results presented in this study (concerning our findings about the impact of coaching on performance, as well as other researchers' findings about this phenomenon) one concern that can be expressed is the relatively small to medium effect size of coaching on performance. Following Cohen (1976), effect sizes of $r=.10$ can be categorized as small, $\mathrm{r}=.30$ as medium and $\mathrm{r}=.50$ as large. In the case of our study, effect size, measured using Pearson's correlation coefficient ranged from a minimum of $r=.170$ in our study with sample \#2 to a maximum of .249 with sample \#1. Despite the fact that our results are of similar order as those other found in the literature, a question might be raise as to whether coaching could explain a significant proportion of the variance in performance.

Following this line of inquiry, one aspect that has been neglected almost completely in the literature is the identification of mediators between coaching and performance. Identifying the mediating variables in any relationship is invaluable because it explains how the relationship works. Unfortunately, research in coaching has given little attention to this phenomenon and with the exceptions of Pousa (2012) and Pousa and Mathieu (2014) no studies have provided a rationale explaining why performance should increase after coaching interventions were conducted. In that aspect, it was found that incorporating mediators in the relationship between coaching and performance can explain a significantly higher percentage of variance (Pousa and Mathieu, 2014). Further research could continue in this line of inquiry and identify additional mediators between coaching and performance.

Another avenue of research concerns the use of LMX as a framework for modeling coaching relationships. Given the high quality of the relationship between the manager and the subordinate in a coaching exchange, scholars used LMX as the main theoretical framework to understand these exchanges (Agarwal et al., 2009; Onyemah, 2009; Pousa, 2012; Pousa and Mathieu, 2014; Trépanier, 2010). One question that can be asked, though, is about the difference between coaching and LMX. If coaching can be understood as a high-quality LMX relationship, what makes it different from LMX? If a manager uses LMX as a leadership style, is he coaching? Are LMX and coaching one similar construct or are they different? These questions also open up new avenues for research.

Finally, although LMX proved to be a useful and convenient theoretical framework to study coaching, are there other theories that can provide additional clues to understanding coaching? Recently it was suggested that Goal-setting theory could be a useful framework to study coaching (Grant, 2011) but its use in coaching research is still underrepresented. Identifying and using additional theoretical frameworks that can expand our understanding of coaching is another avenue for future research.

\section{References}

Agarwal, R., Angst, C. M. \& Magni, M. (2009). The performance effects of coaching: a multilevel analysis using hierarchical linear modeling, The International Journal of Human Resource Management, 20(10), 2110-2134.

Bagozzi, R. \& Yi, Y. (1988). On the Evaluation of Structural Equation Models, Journal of the Academy of Marketing Science, 16(1), 74-84.

Byrne, B. (2010). Structural Equation Modeling with AMOS: basic concepts applications and programming (2nd edition). New York, NY: Rutledge.

Cassidy, M.F. \& Medsker, K.L. (2009). Coaching and Performance Improvement, Performance Improvement Quarterly, 21(4), 3-4.

Cohen, J. (1976). Statistical Power Analysis for the Behavioral Sciences. Orlando, FL: Academic Press Inc., Revised 


\section{Edition.}

Corcoran, K., Petersen, L., Baitch, D. \& Barret, M. (1995). High Performance Sales organizations: Achieving competitive advantage in the Global Marketplace. Chicago, IL: IRWIN Professional Publications.

Cote, J. A. \& Buckley, M. R. (1987). Estimating Trait, Method and Error Variance: Generalizing Across 70 Construct Validation Studies, Journal of Marketing Research, 24(3), 315-318.

Cron, W. L., Dubinsky, A. J. \& Michaels, R. E. (1988), The influence of career stages on components of salesperson motivation, Journal of Marketing, 52(1), 78-92.

D’Abate, C., Eddy, E. \& Tannenbaum, S. (2003). What's in a name? A Literature-based Approach to Understanding Mentoring, Coaching and Other Constructs that Describe Developmental Interaction, Human Resource Development Review, 2(4), 360-384.

Dansereau, F. Jr., Graen, G. \& Haga, W. J. (1975). A Vertical Dyad Linkage Approach to Leadership within Formal Organizations : A Longitudinal Investigation of the Role Making Process, Organizational Behavior and Human Performance, 13(1), 46-78.

Deeter-Schmelz, D., Kennedy, K. N. \& Goebel, D. J. (2002). Understanding Sales Manager Effectiveness: Linking Attributes to Sales Force Values, Industrial Marketing Management, 31(7), 617-626.

Deeter-Schmelz, D., Goebel, D. J. \& Kennedy, K. N. (2008). What are the Characteristics of an Effective Sales Managers? An Exploratory Study Comparing Salesperson and Sales Manager Perspectives, Journal of Personal Selling and Sales Management, 28(1), 7-20.

Ellinger, A. D. (2003). Antecedents and Consequences of Coaching Behaviour, Performance Improvement Quarterly, 16(1), 5-28.

Ellinger, A. D. \& Bostrom, R. (1999). Managerial Coaching Behaviors in Learning Organizations, Journal of Management Development, 18(9), 752-64.

Ellinger, A. D., Ellinger, A. E. \& Keller, S. B. (2003). Supervisory Coaching Behavior, Employee Satisfaction, and Warehouse Employee Performance: A Dyadic Perspective in the Distribution Industry, Human Resource Development Quarterly, 14 (Winter), 435-458.

Ellinger, A. E., Ellinger, A. D. \& Keller, S. (2005). Supervisory coaching in a logistics context, International Journal of Physical Distribution and Logistics Management, 35(9), 620-636.

Evered, R. D. \& Selman, J. C. (1989). Coaching and the Art of Management, Organizational Dynamics, 18(2), 16-32.

Fang, E., Palmatier, R. W. \& Evans, K. R. (2004). Goal-Setting Paradoxes? Trade-Offs Between Working Hard and Working Smart: The United States versus China, Journal of the Academy of Marketing Science, 32(Spring), 188-202.

Fornell, C. \& Larcker, D. (1981). Evaluating structural equations models with unobservable variables and measurement error, Journal of Marketing Research, 18, 39-50.

Fournies, F. (1978). Coaching for Improved Work Performance. New York, NY: Van Nostrand Reinhold Company.

Gerbing, D. W. \& Anderson, J. C. (1988). An Updated Paradigm for Scale Development Incorporating Unidimensionality and Its Assessment, Journal of Marketing Research, 25(2), 186-192.

Gerstner, C. R. \& Day, D. V. (1997). Meta-analytic Review of Leader-Member Exchange Theory: Correlates and Constructs Issues, Journal of Applied Psychology, 82(6), 827-844.

Gilley, A., Gilley, J.W. \& Kouider, E. (2010). Characteristics of Managerial Coaching, Performance Improvement Quarterly, 23(1), 53-70.

Good, D. (1993). Coaching Practices in the Business-to-Business Environment. The Journal of Business and Industrial Marketing, 8(2), 53-60.

Graen, G. B. \& Uhl-Bien, M. (1995). Relationship-Based Approach to Leadership: Development of Leader-Member Exchange (LMX) Theory of Leadership over 25 years: Applying a multi-level multi-domain perspective, Leadership Quarterly, 6(Summer), 219-247.

Graham, S., Wedman, J. \& Garvin-Kester, B. (1993). Manager Coaching Skills: Development and Application, 
Performance Improvement Quarterly, 6(1), 2-13.

Graham, S., Wedman, J. \& Garvin-Kester, B. (1994). Manager Coaching Skills: What makes a good coach?, Performance Improvement Quarterly, 7(2), 81-94.

Grant, A.M. (2011) Workplace, Executive and Life Coaching: An Annotated Bibliography from the Behavioural Science and Business Literature ( $1^{\text {st }}$ Jan 2011), Coaching Psychology Unit, University of Sydney, Australia.

Grant, A. M. \& Cavanagh, M. J. (2004). Toward a profession of coaching : Sixty-five years of progress and challenges for the future, International Journal of Evidence Based Coaching and Mentoring, 2(1), 1-16.

Guthery, D. \& Lowe, B. (1992). Translation Problems in International marketing Research, The Journal of Language for International Business, 4(1), 1-14.

Hagen, M. S. (2012). Managerial Coaching: A Review of the Literature, Performance Improvement Quarterly, 24(4), 17-39.

Hamlin, R. G., Ellinger, A. D. and Beattie, R. S. (2006). Coaching at the heart of managerial effectiveness: A Cross-cultural study of managerial behaviours, Human Resource Development International, 9(3), 305-331.

Hargrove, R. (1995) Masterful Coaching. Extraordinary Results by Impacting People and the Way They Think and Work Together. San Francisco CA: Pfeiffer.

Heslin, P. A., Vandewalle, D. \& Latham, G. P. (2006). Keen to help? Manager's implicit person theories and their subsequent employee coaching, Personnel Psychology, 59(Winter), 871-902.

House, R. J. \& Aditya, R. N. (1997). The Social Scientific Study of Leadership : Quo Vadis?, Journal of Management, 23(3), 409-473.

Ilies, R., Nahrgang, J. D. \& Morgeson, F. P. (2007). Leader-Member Exchange and Citizenship Behaviors: A Meta-Analysis, Journal of Applied Psychology, 92(1), 269-277.

Ingram, T. N., LaForge, R., Locander, W., MacKenzie, S. and Podsakoff P. (2005). New Directions in Sales Leadership Research, Journal of Personal Selling and Sales Management, 25(2), 137-154.

Ives, Y. (2008). What is Coaching? An Exploration of Conflicting Paradigms, International Journal of Evidence Based Coaching and Mentoring, 6(2), 100-113.

Joo, B. (2005). Executive Coaching: A conceptual framework from and integrative review of practice and research, Human Resource Development Review, 4, 462-488.

Kilburg, R, (1996). Toward a Conceptual Understanding and Definition of Executive Coaching, Consulting Psychology Journal: Practice and Research, 48(2), 134-144.

Kline, R. B. (2011). Principles and Practice of Structural Equation Modeling, The Guilford Press, New York, NY, 3rd Edition.

Lee, J. (2005). Effects of Leadership and Leader-Member Exchange on Commitment, Leadership \& Organization Development Journal, 26(7/8), 655-672.

Liden, R. C. \& Maslyn, J. M. (1998). Multidimensionality of Leader-Member Exchange: An Empirical Assessment through Scale Development, Journal of Management, 24(1), 43-72.

Mathieu, A. \& Pousa, C. (2011). Does Supervisory Coaching Behaviour Reduce Salespeople's Lies?, International Journal of Evidence Based Coaching and Mentoring, 9(1), 16-28.

Mathieu, A., Bruvold, N. \& Ritchey, P. (2000). Subcultural Research on Organizational Commitment with the 15 OCQ Invariant Instrument, Journal of Personal Selling and Sales Management, 20(3), 129-138.

Maxwell, J. A. (1997). Designing a Qualitative Study. In L. Bickman and D. J. Rog (eds), Handbook of Applied Social Research Methods (p. 69-98), Thousand Oaks, CA : Sage Publications

McLean, G., Yang, B., Kuo, M., Tolbert, A. \& Larkin, C. (2005). Development and Initial Validation of an Instrument Measuring Managerial Coaching Skills, Human Resource Development Quarterly, 16(2), 157-178.

Nunnally, J. C. (1978). Psychometric Theory, McGraw-Hill, New York, NY.

Onyemah, V. (2009). The Effects of Coaching on Salespeople's Attitudes and Behavior, European Journal of Marketing, 43(7/8), 938-960. 
Orth, C. D., Wilkinson, H. E. \& Benfari, R. C. (1987). The Manager's Role as a Coach and Mentor, Organizational Dynamics, 15(4), 66-74.

Podsakoff, P. M., MacKenzie, S. B., Lee, J.-Y. \& Podsakoff, N. P. (2003). Common Method Biases in Behavioral Research: A Critical Review of the Literature and Recommended Remedies, Journal of Applied Psychology, 88(5), 879-903.

Pousa, C. \& Mathieu, A. (2010). Sales Managers' Motivation to Coach Salespeople: An exploration using Expectancy Theory, International Journal of Evidence Based Coaching and Mentoring, 8(1), 34-50.

Pousa, C. \& Mathieu, A. (2014). Boosting Customer-Orientation through Coaching: A Canadian Study, International Journal of Bank Marketing, 32(1), 60-81. doi: 10.1108/IJBM-04-2013-0031.

Pousa, C. E. (2012). The Impact of Coaching on Salesperson's Performance and the Mechanisms that regulate this Relationship, doctoral dissertation, Faculté d'Administration, Université de Sherbrooke.

Rich, G. (1998). The constructs of Sales Coaching: Supervisory feedback, role modeling and trust, Journal of Personal Selling \& Sales Management, 18(Winter), 53-63.

Richardson, L. (2009). Sales Coaching: Making the great leap from Sales Manager to Sales Coach. New York: McGraw-Hill, 2nd edition.

Robson, C. (2002). Real World Research. Malden, MA: Blackwell Publishing, $2^{\text {nd }}$ edition.

Schmitt, N. (1994). Method Bias: The Importance of Theory and Measurement, Journal of Organizational Behavior, 15(5), 393-398.

Sparrowe, R. T. \& Liden, R. C. (1997). Process and Structure in Leader-Member Exchange, The Academy of Management Review, 22(2), 522-535.

Spector, P. E. (1987). Method Variance as an Artifact in Self-reported Affect and Perceptions at Work: Myth or Significant Problem?, Journal of Applied Psychology, 72(3), 438-443.

Spector, P. E. (1994). Using Self-report Questionnaires in OB Research: A Comment on the Use of a Controversial Method, Journal of Organizational Behavior, 15(5), 385-392.

Spector, P. E. (2006). Method Variance in Organizational Research: Truth or Urban Legend?, Organizational Research Methods, 9(2), 221-232.

Trépanier, C. (2010). Le coaching du directeur et la performance du vendeur: une approche relationnelle, doctoral dissertation, Faculté d'Administration, Université de Sherbrooke.

Whitmore, J. (1985). Coaching for Performance: A Practical Guide to growing your own Skills. San Diego, CA: Pfeiffer. 